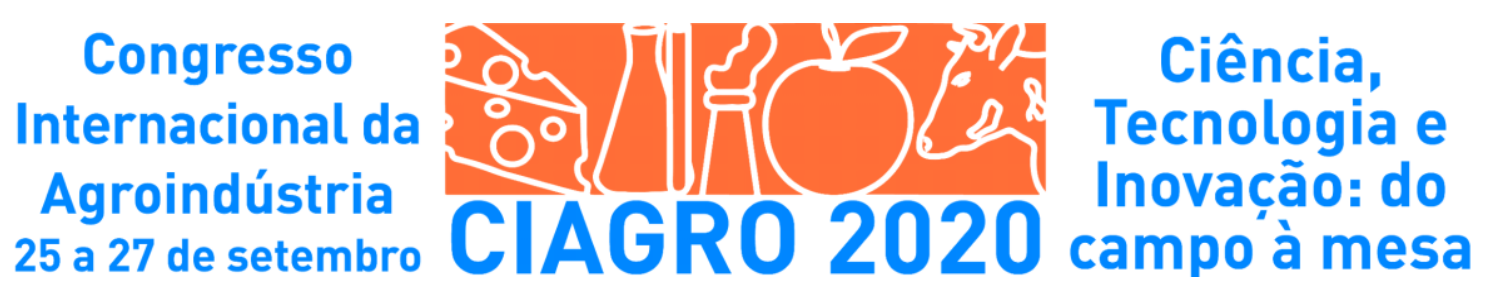

\title{
BIORREMEDIAÇÃO DE SOLOS E ÁGUAS CONTAMINADOS COM HIDROCARBONETOS: REVISÃO DE LITERATURA
}

\section{BIORREMEDIATION OF SOILS AND WATERS CONTAMINATED WITH HYDROCARBONS: AN REVIEW}

\author{
Laís Mendes Moura da Silva ${ }^{1}$; Cristina Giatti Marques de Souza ${ }^{2}$; Rosane Marina Peralta ${ }^{3}$ Rafael \\ Castoldi $^{4}$
}

\begin{abstract}
Resumo
Os acidentes ambientais tem sido uma preocupação em todo o mundo, principalmente àqueles de difícil reversão. O derrame de petróleo em solos e lixiviado nas águas, por exemplo, vem intrigando pesquisadores na sociedade atual. Seus derivados são compostos de hidrocarbonetos chamados de BTEX (benzeno, tolueno, etilbenzeno e xileno). Este grupo contém moléculas altamente tóxicas e de difícil biodegradação. Para isso faz-se necessário estudos que possibilitam a remediação desses compostos de modo que diminua a contaminação e os seus efeitos adversos a população e ao meio ambiente. A biorremediação é uma das saídas para a eliminação desse grupo de moléculas, nesse processo utilizam-se de microrganismo capazes de degradar essa matéria, como fungos e bactérias. O presente trabalho discute os processos de degradação do BTEX abordando os microrganismos com capacidade degradativa desses compostos.
\end{abstract}

Palavras-Chave: Petróleo, hidrocarbonetos, biorremediação.

\begin{abstract}
Environmental accidents have been a concern worldwide, especially those that are difficult to reverse. The oil spill in soils and leachate in the waters, for example, has intrigued researchers in today's society. Its derivatives are composed of hydrocarbons called BTEX (benzene, toluene, ethylbenzene and xylene). This group contains highly toxic molecules that are difficult to biodegrade. For that, it is necessary studies that enable the remediation of these compounds in a way that reduces the contamination and its adverse effects on the population and the environment. Bioremediation is one of the ways to eliminate this group of molecules, in this process they use microorganisms capable of degrading this matter, such as fungi and bacteria. The present work discusses the degradation processes of BTEX addressing microorganisms with degradative capacity of these compounds.

\footnotetext{
${ }^{1}$ Biotecnologia, Universidade Estadual de Maringá, laiismendes76@gmail.com

${ }^{2}$ Professora Doutora no Departamento de Bioquímica da Universidade Estadual de Maringá, cgmsouza@uem.br

${ }^{3}$ Professora Doutora no Departamento de Bioquímica da Universidade Estadual de Maringá, rmperalta@ue.br

${ }^{4}$ Professor Doutor no Departamento de Bioquímica da Universidade Estadual de Maringá, rcastoldi@uem.br
} 
Keywords: Oil, hydrocarbons, bioremediation.

\section{Introdução}

O solo é a camada superficial da crosta terrestre, o que leva a exposição a vários tipos de danos, muitas vezes são causados pela ação do homem, é a camada que mais sofre impactos com danos diretos e indiretos. Toda forma de liberação de matérias nocivas ao solo prejudicam a vida biológica naquele meio. Entre as formas de maior contaminação está o derramamento de compostos químicos como o petróleo e seus derivados (HEIDERSCHEIDT et al., 2016).

A água é o mais importante recurso natural para sobrevivência na Terra, no organismo ela representa cerca de $70 \%$ da massa corporal, atua como um importante transportador de substâncias de manutenção do corpo. No ambiente é muito utilizada para o uso doméstico, industrial, agrícola, navegação, entre outros. A navegação pelos rios e mares são frequentes, nas embarcações contém desde pessoas, alimentos e combustíveis como o petróleo. Dessa forma, há uma necessidade de se tomar um cuidado especial com esse recurso (OLIVEIRA et al., 2018).

O petróleo é um importante elemento utilizado como combustível em transportes e geração de energia, é uma substância natural que se encontra em estado líquido. É um composto altamente tóxico, se apresenta com uma densidade menor do que da água e é um elemento formado por grupos hidrocarbonetos alifáticos, acíclicos e aromáticos (MORAES, 2014). No Brasil, tem-se alguns acidentes de derrames de gasolina em centros de distribuição. Um desses acidentes foi em janeiro de 2012, um derramamento no mar ocasionado devido à uma operação de transbordo de uma monoboia da Transpetro, atingiu a praia em Tramandaí, RS. O acidente derramou cerca de 1,2 milhões de litros de óleo no mar (LEAL et al, 2016).

Os compostos derivados do petróleo possuem grande importância ambiental, eles são chamados de BTEX de cadeias aromáticas, grupo composto pelo benzeno, tolueno, etilbenzeno e xilenos, são moléculas com alta toxicidade, pois eles possuem um potencial mutagênico, teratogênico e carcinogênico (LEAL et al, 2016). O benzeno, por exemplo, é considerado uma substância cancerígena e hemotóxica, essa classificação é decorrente de sua metabolização. A hematoxicidade é caracterizada principalmente pela diminuição das células sanguíneas, resultando em quedas no número dos elementos do sangue, esse evento é um possível indicador de leucemia 
mieloide aguda precoce. Além disso, este composto causa também alterações de cromossomos que são consideradas a explicação mais plausível para sua carcinogenicidade (COSTA, GOLDBAUM, 2016).

Os BTEX são moléculas lipossolúveis o que possibilita o aumento da continuidade desses compostos no meio ambiente, sendo assim, dificulta a biodegradação natural (LEAL et al, 2016). Nos rios e mares o derramamento destes compostos diminui o nível de atividade fotossintéticas dos fitoplâncton e de algas e seu efeito impermeabilizante possibilitam que aves, mamíferos e animais marinhos perdem a flutuabilidade e o isolamento térmico levando a morte (MOREIRA, 2016). No solo, são esses compostos se ligam a moléculas presentes nesse meio, onde permanecem por milhares de anos, alterando a biota do solo, causando infertilidade entre outros problemas, implicando diretamente na produção agrícola afetando toda a população em geral por meio da cadeia alimentar (JASMINE, J.; MUKHERJI, S., 2019).

A presença desses elementos tóxicos leva a diversos problemas ambientais que influenciam direta e indiretamente os seres humanos, além de uma influência ainda maior a outras formas de vida do ecossistema, desta forma, faz-se necessário estudos a fim de remediar esses poluentes (HEIDERSCHEIDT, et al., 2016).

Os processos de remediação como os físico-químicos, são altamente caros, além de estar propício a acumular outras substâncias que fazem parte dele, que também podem ser prejudiciais à saúde. Sendo assim, a remediação utilizando microrganismos seria vantajoso no ponto de vista econômico, além de evitar outras contaminações como no processo físico-químico (SILVA, 2018).

A biorremediação é uma dessas formas de remediação que se utiliza organismos, como plantas, fungos, microrganismos, que em sua composição possuem enzimas que são capazes de eliminar a contaminação em solos e águas. A velocidade com que essas moléculas degradam o poluente é discrepante, isso porque, cada substância tem uma resistência, por conta de sua estrutura e concentrações diferentes no ambiente (HEIDERSCHEIDT, et al., 2016).

Nos últimos anos tem-se observados o uso de bactérias degradadoras de hidrocarbonetos, pela sua eficiência e seu baixo custo. As bactérias têm a propriedade de transformar resíduos tóxicos a não-tóxicos, sendo assim, há a redução significativa dos efeitos nocivos à saúde e meio ambiente. Esse tipo de processo é executado in situ, ou seja, o tratamento percorre sem que haja um transtorno aos ecossistemas (GHOREISHI et al., 2017). 
As bactérias que vivem em locais contaminados e a caracterização das mesmas podem auxiliar na biorremediação. Os microrganismos como Pseudomonas spp., Bacillus spp., Micrococcus spp., Rhodoccucos spp., Entrobacter spp., Mycobactena spp., Modococci spp. e Acinetobacter spp podem degradar compostos do petróleo, porém em taxas diferentes, sendo importante avaliá-los quanto a capacidade de degradação, para obter um bom resultado (GHOREISHI et al., 2017).

Os fungos também são biodegradadores e fazem parte da natureza, em águas, solos e ar, contribuem para a decomposição da matéria orgânica. $\mathrm{O}$ uso de fungos filamentosos e seus metabólitos têm se mostrado de grande potencial na degradação de compostos tóxicos por terem alto potencial degradativo, algumas espécies que assimilam os hidrocarbonetos são do gênero Aspergillus e Penicillium, sendo uma característica individual das espécies (SOUSA et al., 2016).

Portanto, este trabalho avalia alguns tipos de biorremediação, comparando os tratamentos com diferentes microrganismos visando a degradação do grupo de hidrocarbonetos BTEX.

\section{Desenvolvimento}

$\mathrm{Na}$ revisão de literatura, visando aprofundar o conhecimento sobre este assunto, foram abordadas questões como, o grupo de hidrocarbonetos de cadeia aromática, suas classificações, os riscos que esses compostos possuem e os diferentes processos de biorremediação desses compostos em águas e solos.

\subsection{Discussão}

\subsubsection{Hidrocarbonetos de cadeia monoaromática}

Hidrocarbonetos de cadeia benzênica são os que apresentam maior toxicidade aos seres vivos, associados a efeitos crônicos e cancerígenos, pois possuem uma degradação lenta, permanecendo por muito tempo em contato com as células do organismo. Essas moléculas tóxicas originam-se da combustão incompleta da matéria orgânica e são altamente perigosos, pois no ambiente se dispersam de forma que as moléculas se tornem mais complexas (LEITE, et. al. 2017). A dispersão desses compostos no ambiente é facilitada pelo transporte de solo e águas em decorrência da solubilidade e volatilidade devido às pequenas cadeias carbônicas compostas de 6 a 8 carbonos (NESPECA, 2018). 
https://doi.org/10.31692/ICIAGRO.2020.0393

Outra propriedade a ser considerada é a solubilidade, capacidade de um determinado constituinte em ser dissolvido em água. A potência de ser dissolvido acontece pela presença de etanol na composição das gasolinas automotivas intensificando a solubilidade, mobilidade e persistência dos compostos BTEX na matriz contaminada. A temperatura é a propriedade físicoquímica que garante a redução da densidade do contaminante, desta forma, a mobilidade dos compostos tendem a aumentar na elevação de temperatura e assim há a redução das características (CAVALLARI,2017).

As propriedades físicas desses compostos interferem no impacto do ambiente e a alta toxicidade quando solúvel em água ou na presença de outros compostos, estão demandando uma atenção na remediação ambiental, principalmente o processo de biomonitoramento. Esses compostos possuem características relativamente importantes a considerar para que se realize esse tipo de procedimento. Listadas na tabela 1 (OSÓRIO, 2018).

Tabela 1- Propriedades físico química dos BTEX.

\begin{tabular}{|c|c|c|c|c|c|c|c|}
\hline Composto & $\begin{array}{l}\text { Peso } \\
\text { molecula } \\
\text { r } \quad\left(\mathrm{g}, \mathrm{mol}^{-}\right. \\
\text {1) }\end{array}$ & $\begin{array}{l}\text { Solubilidad } \\
\text { e }\left(\mathrm{mg}^{-L^{-1}}\right)^{25^{*}}\end{array}$ & $\begin{array}{l}\text { Constante } \\
\text { Dielétrica }^{2} \\
0\end{array}$ & $\begin{array}{l}\text { Densidad } \\
\text { e } \quad(\text { g.cm } \\
\left.{ }^{3}\right)^{25}\end{array}$ & $\begin{array}{l}\text { Log } \\
\text { Kow }_{\text {ow }}\end{array}$ & $\begin{array}{l}\text { Ponto de } \\
\text { Ebuliçã } \\
o\left({ }^{\circ} \mathrm{C}\right)\end{array}$ & $\begin{array}{l}\text { Ponto } \\
\text { de } \\
\text { Fusã } \\
\left.\text { o ( }{ }^{\circ} \mathrm{C}\right)\end{array}$ \\
\hline Benzeno & 78,112 & 1790 & 2,28 & 0,8765 & $\begin{array}{l}+2,1 \\
3\end{array}$ & 80,08 & 5,53 \\
\hline Tolueno & 92,139 & 526 & 2,38 & 0,8623 & $\begin{array}{l}+2,6 \\
9\end{array}$ & 110,60 & $\begin{array}{l}- \\
95,00\end{array}$ \\
\hline $\begin{array}{l}\text { Etilbenzen } \\
\text { o }\end{array}$ & 106,165 & 169 & 2,41 & 0,8626 & $\begin{array}{l}+2,7 \\
6\end{array}$ & 136,20 & $\begin{array}{l}- \\
94,95\end{array}$ \\
\hline o-Xileno & 106,165 & 178 & 2,30 & 0,8755 & $\begin{array}{l}+3,0 \\
0\end{array}$ & 144,40 & $\begin{array}{l}- \\
25,16\end{array}$ \\
\hline m-Xileno & 106,165 & 161 & 2,30 & 0,8598 & $\begin{array}{l}+3,0 \\
0\end{array}$ & 139,10 & $\begin{array}{l}- \\
47,85\end{array}$ \\
\hline p-Xileno & 106,165 & 162 & 2,30 & 0,8565 & $\begin{array}{l}+3,0 \\
0\end{array}$ & 138,30 & 13,30 \\
\hline
\end{tabular}

*Solubilidade em água a $25^{\circ} \mathrm{C}$ 


\subsubsection{Benzeno}

O benzeno é um hidrocarboneto aromático classificado como poluente onipresente do ar, pois está associado a uma combustão juntamente com a gasolina que é liberado principalmente de veículos. A exposição em humanos ao benzeno induz estresse oxidativo em células do corpo, que resulta em quebras na fita do DNA, gerando mutações genéticas cromossômicas, aberrações e micronúcleos. Essas transformações são de grande importância e relevância, sendo que, são as principais causas do surgimento do câncer ao sofrerem esses eventos (LOOMIS, et al. 2017). Na figura 1 pode-se observar a sua forma estrutural (BEZERRA, 2017).

Figura 1- Estrutura molecular do benzeno.

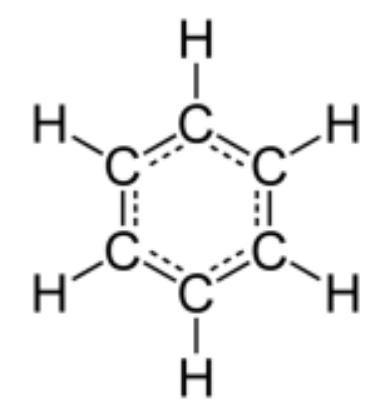

O benzeno é uma molécula de alto risco para com sua toxicidade, ele está presente principalmente em postos de abastecimento como um importante produto químico orgânico juntamente com a gasolina. A exposição dessa molécula em altas doses e a curto prazo pode desenvolver anestesia do sistema nervoso central e falência de órgãos, enquanto as exposições a longo prazo em baixas doses causam diminuição na contagem de células sanguíneas periféricas, envenenamento crônico por benzeno e até neoplasias hematológicas como SMD e leucemia, além de mutações cromossômicas (GUO et al., 2019).

\subsubsection{Tolueno}

O tolueno é um solvente orgânico volátil, altamente inflamável e também pode ser identificado pelo ar. É uma molécula pouco solúvel em água (quando comparado com o benzeno), porém com a presença de um composto orgânico sua solubilidade aumenta. É um composto tóxico devido a capacidade de promover morte celular e ter um efeito neurotóxico em humanos e animais (SOARES, et al., 2016). Na figura 2 pode-se observar a sua forma estrutural (BEZERRA, 2017). 
Figura 2- Estrutura molecular do tolueno.

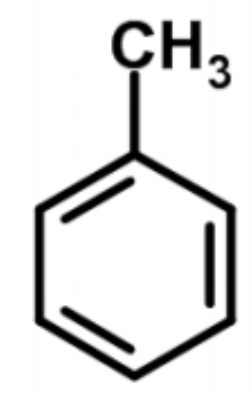

\subsubsection{Xileno}

O termo xileno refere-se ao grupo de três isômeros orto-xileno, meta-xileno e para-xileno que se diferem em função da organização dos grupos metila. É um líquido incolor, inflamável, praticamente insolúvel em água. Os xilenos são encontrados principalmente no petróleo utilizados em fragrâncias sintéticas e na fabricação de tintas, vernizes e borracha. São também lançados na atmosfera por meio de emissões fugitivas de fontes industriais, emissão veicular, volatilização de solventes e incêndios florestais. A exposição a esse composto de misturas de xileno resulta em alguns sintomas como irritação dos olhos, nariz e garganta e efeitos neurológicos. O contato dessa molécula vias aéreas, pode afetar o sistema nervoso central e dependendo das concentrações provoca fortes dores de cabeça, vertigens, fadiga e tremores. A USEPA classifica os xilenos no Grupo D, como não carcinogênico para humanos (CETESB, 2016). Na figura 3 observa-se a forma molecular dos 3 isômeros (SILVA et al., 2019).

Figura 3- Isômeros orto-xileno, meta-xileno e para-xileno. 
<smiles>Cc1ccccc1C</smiles><smiles>Cc1cccc(C)c1</smiles>

p-xileno<smiles>Cc1ccc(C)cc1</smiles>

$m$-xileno

\subsubsection{Etil-Benzeno}

O etilbenzeno é utilizado como um aditivo na gasolina e pode estar presente em produtos como tintas, pesticidas e plásticos. Como os outros BTEX é altamente volátil e como o tolueno, o contato crônico com esse composto resulta em sintomas similares apresentados acima. É também muito utilizado na produção do estireno a partir da desidrogenação do etilbenzeno (OLIVEIRA, 2017)

Segundo o Departamento de Saúde e Serviços Humanos dos EUA, o etilbenzeno foi classificado como um possível cancerígeno com base em estudos de animais de laboratório pela IARC, realizados em 2009. Na figura 4 observa-se a forma molecular do etilbenzeno (OLIVEIRA, 2017).

Figura 4- Estrutura molecular do etilbenzeno.

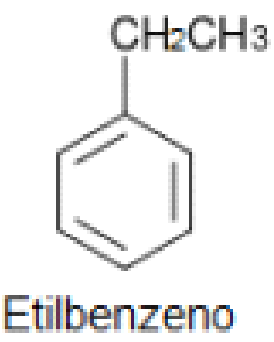

\subsubsection{Biorremediação}

Alguns estudos mostram a importância dos microrganismos em benefício da humanidade, esses testes começaram desde 1856 com Louis Pasteur. Na época o francês não imaginava o grande potencial que os microrganismos tinham em remediar áreas contaminadas. Mediante a descoberta foram surgindo diversas alternativas para tentar minimizar problemas de contaminação ambiental, uma dessas técnicas é de biorremediação. 
https://doi.org/10.31692/ICIAGRO.2020.0393

A biorremediação é um processo que utiliza principalmente microrganismos, plantas, enzimas microbianas ou vegetais para desintoxicar e degradar contaminantes no solo e em outros ambientes, com a finalidade de restaurar a saúde do ecossistema (GOUMA et al., 2014). Há interesse no efeito de fatores ambientais sobre a capacidade de biorremediação de compostos xenobióticos que estendem a meia-vida em ecossistemas terrestres e aquáticos. Esse processo é caracterizado pela inserção desses organismos ou enzimas a fim de reduzir o efeito de um composto tóxico, transformando em compostos inofensivos ao meio ambiente (ORYAN, A., et al., 2018).

\subsubsection{Remediação por método físico-químico}

Os métodos físicos químicos para a remediação dos solos e águas contaminados pelos BTEX, são amplamente utilizados. Segundo Zhou (2019) os processos de oxidação têm ganhado uma grande importância para essa utilização devido a eficiência da remoção de solos e águas contaminados. Os oxidantes químicos tem o poder de converterem poluentes orgânicos em inofensivos ou menos prejudiciais, alguns utilizados são peróxido de hidrogênio, persulfato, permanganato, ozônio e o processo de Fenton.

No entanto, a utilização desses métodos químicos, podem alterar a geoquímica do solo devido a sua instabilidade, esses compostos reagem com microrganismos presentes no meio, afetando a vida biológica nesse ambiente e produzindo outros tipos de substâncias que não são favoráveis ao ambiente.

\subsubsection{Biorremediação utilizando bactérias}

Entre os materiais biológicos usadas, as células bacterianas são preferidas como biomaterial adequado para a biorremediação devido à sua habilidade de estar presente em toda a parte em forma de colônias, capacidade de crescer sob controle condições e taxas mais rápidas de remediação da poluição devido à seu metabolismo (PRABHAKARAN et al., 2019).

Os microrganismos podem utilizar os compostos petroquímicos como única fonte de carbono e energia esse efeito pode resultar a mudanças mensuráveis na composição do combustível. Esse processo é classificado como relativamente barato, e quando comparado a outros tipos de remediação é o mais seguro (WANG et al., 2019). 
A biorremediação in situ é a mais empregada no mundo. Contudo, os microrganismos devem estar ativos para desempenharem a sua tarefa de biodegradação. Como na figura a seguir (ANDRADE et al., 2016).

Figura 5 - Esquema de simplificado da ação de microrganismos em processos de biorremediação (ANDRADE et al., 2016).

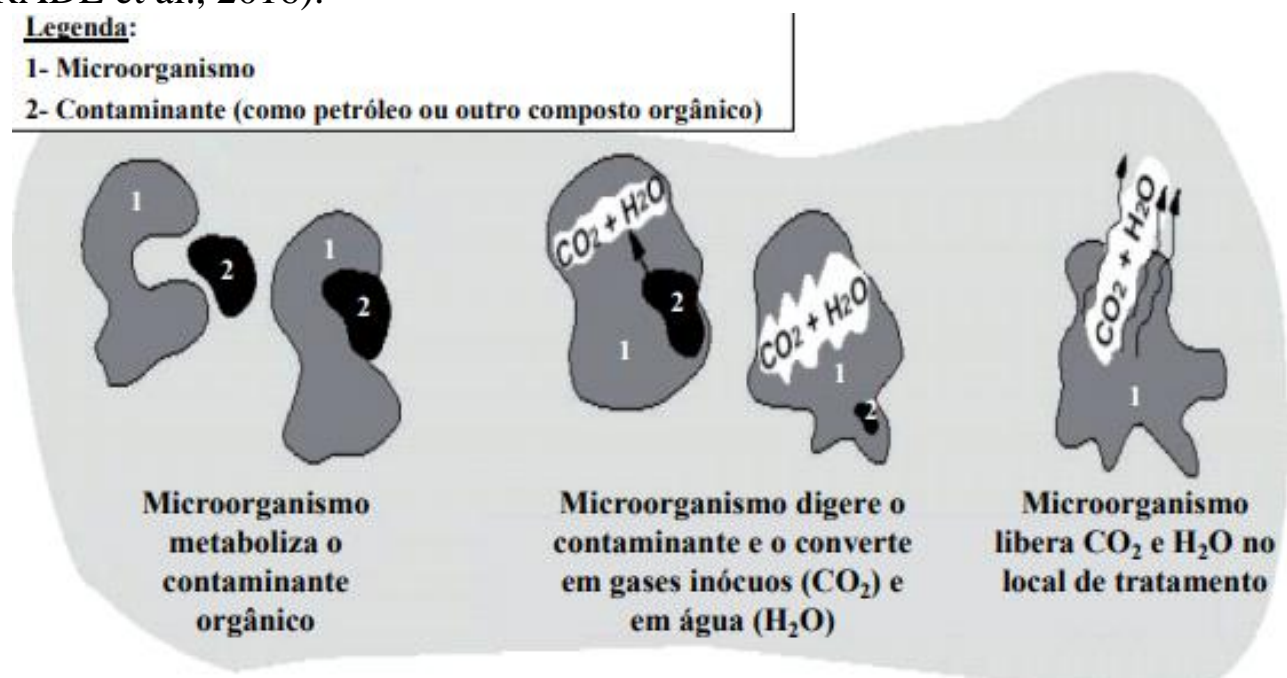

No trabalho de Mazzeo (2016) realizado ex situ, foram selecionadas cincos espécies de bactérias que possuem um grande potencial de biodegradação de BTEX. O ensaio realizado pelos pesquisadores é conhecido como DBO, nesse processo ocorre a oxidação da matéria orgânica com o consumo de Oxigênio e liberação de gases como gás carbônico. Neste trabalho após seleção de bactérias foi adicionado diferentes concentrações dos cincos tipos de BTEX, em culturas de bactérias pré-selecionadas separadamente em vidros âmbar onde foram mantidos por 20 dias sob agitação.

Nessas condições os microrganismos possuíram como única fonte de carbono os hidrocarbonetos. Os resultados apresentados foram obtidos através dos valores de consumo de oxigênio, logo, podemos inferir que os microrganismos consumiram a presente matéria orgânica (BTEX). 
Diversos microrganismos foram encontrados usando MacConkey e ágar CLED, como Acinetobacter lwoffi, P. putida e bacilos Gram negativos não fermentativos. No ágar-sangue e ágar-chocolate, outras duas espécies de bactérias foram identificadas Moraxella sp e Brevundimonas diminuta. Os resultados na identificação de microrganismos biodegradáveis por BTEX são mostrados na Tabela 2.

Tabela 2 - Crescimento bacteriano na ausência e presença de quatro concentrações de BTEX em Meio Bushnell - Haas

\begin{tabular}{|c|c|c|c|c|c|}
\hline \multirow[t]{2}{*}{ Strain } & \multirow{2}{*}{$\frac{\text { Glucose } 0.1 \%(\mu \mathrm{L})}{12}$} & \multicolumn{4}{|c|}{$\operatorname{BTEX}(\mu \mathrm{L} / 3 \mathrm{~mL})$} \\
\hline & & 5 & 10 & 15 & 20 \\
\hline Acinetobacter lwoffii & ++ & - & - & - & - \\
\hline$B G N$ & + & - & - & - & - \\
\hline Pseudomonas putida & +++ & ++ & + & + & + \\
\hline Moraxella sp & ++ & - & - & - & - \\
\hline Brevundimonas diminuta & +++ & - & - & - & - \\
\hline A. Iwoffii, BGN, P. putida, & & & & & \\
\hline Moraxella sp, B. diminuta & +++ & ++ & + & + & + \\
\hline Pseudomonas aeruginosa ATCC 27853 & +++ & ++ & ++ & + & + \\
\hline
\end{tabular}

$(+)$ : turbidez positiva, baixo crescimento.

$(++)$ : turbidez positiva, crescimento moderado.

$(+++)$ : turbidez positiva, crescimento intenso.

(-): turbidez negativa, sem crescimento.

A bactéria $P$. putida causou turbidez em meio de glicose (controle) e em todos os meios com BTEX. A bactéria A. lwoffii, Moraxella sp, B. diminuta e NFGNB causaram turbidez no meio contendo apenas glicose, e não cresceram na presença de BTEX, independentemente na concentração testada. A espécie $P$. aeruginosa ATCC 27853, usado como controle, causou turbidez em todos os tubos, seja na presença ou ausência de BTEX. Os tubos contendo as cinco linhagens de bactérias de o efluente da refinaria de petróleo também causou turbidez. A replicação em placas obtidas desses tubos com positivo turbidez, ou seja, com as espécies $P$. putida, consórcio das cinco bactérias e $P$. aeruginosa, revelou que $P$. putida estava presente na replicação de ambos P. putida e tubos bacterianos de consórcio. Portanto, $P$. putida provou ser a única bactéria isolada de o efluente bruto da refinaria capaz de crescer na presença da BTEX.

A bactéria $P$. aeruginosa é uma gram negativa em forma de bastonete, é uma boa representante dentro de grupos de microrganismos aeróbicos com habilidade de biodegradação 
aromática. Em estudos apresentados, o uso da bactéria tem-se mostrado bastante eficiente (Kurzbaum, 2017)

\subsubsection{Biorremediação utilizando fungos}

Os fungos estão em grande quantidade distribuídos na natureza, encontrados na água, no solo, sobre os animais e vegetais vivos, entre outros. A utilização de fungos filamentosos e seus metabólitos nos processos de biorremediação vem crescendo, em virtude do alto potencial degradativo, biossortivo e dos mecanismos de resistência em condições ambientais adversas. As principais espécies de fungos que assimilam hidrocarbonetos são do gênero Aspergillus e Penicillium, sendo uma característica individual da espécie (SOUZA, 2016).

A vantagem em se utilizar fungos se relaciona com a tolerância a maiores concentrações de produtos tóxicos, à capacidade de crescerem sob condições ambientais de estresse como em meios com baixos valores de $\mathrm{pH}$, e ainda, por suportarem meios pobres em nutrientes. Os fungos apresentam uma maior capacidade de sobrevivência em meios com baixa atividade de água em relação às bactérias e leveduras (RODRIGUES, 2017).

No trabalho de Rodrigues (2017) a amostra utilizada foi uma água contaminada com gasolina e fungo selecionado por meio de cultivo em Ágar Sabouraud Dextrose, acrescido de 0,03 g.L-1 do antibiótico estreptomicina, visando eliminar a proliferação de bactérias, foi o Aspergillus niger AN400. O experimento foi realizado em reator contínuo onde ocorreu duas etapas de alimentação. Na primeira etapa com adição de 0,5 g.L-1 de glicose no afluente e na segunda etapa sem adição de glicose no afluente. A Etapa I foi dividida em duas fases distintas, segundo a não adição (Fase 1) e adição de nutrientes (Fase 2) no afluente, sendo a Fase 1 correspondente às coletas de 1 a 5 e a Fase 2 às coletas de 6 a 10. Na Etapa II foi mantida a adição de nutrientes. Nas Figuras 6 e 7, são apresentadas as concentrações de benzeno, tolueno, etilbenzeno, m e p-xileno e o-xileno do afluente e efluente ao reator de leito fixo e fluxo contínuo com fungos nas Etapas I e II, respectivamente.

Na Etapa I, foram alcançados os percentuais de remoção de $96 \%$ na Fase 1 e $97 \%$ na Fase

2 para benzeno; $95 \%$ e $93 \%$ para tolueno, respectivamente; $65 \%$ e $79 \%$ para etilbenzeno; $89 \%$ e $86 \%$ para m e p-xileno e $87 \%$ e $88 \%$ para o-xileno. Ao se comparar as duas fases, evidenciou-se que a adição de nutrientes não resultou, estatisticamente, em uma diferença significativa nas eficiências de remoção dos poluentes (Figura 6). 
https://doi.org/10.31692/ICIAGRO.2020.0393

Na Etapa II, as remoções médias foram de $88 \%$ para benzeno, $90 \%$ para tolueno, $90 \%$ para etilbenzeno, e de 91\% para m, p e o-xileno. Observou-se a Etapa I com a II, não houve diferença nas eficiências de remoção para tolueno, m e p-xileno e o-xileno . Entretanto, as eficiências de remoção de benzeno e etilbenzeno apresentaram diferença significativa $(p<0,05)$, por meio de cálculos estáticos. Isso mostrou que houve diminuição da eficiência de remoção de benzeno de 96\% (Etapa I) para 88\% (Etapa II) e aumento da eficiência de remoção de etilbenzeno de $72 \%$ (Etapa I) para 90\% (Etapa II). A presença de glicose favoreceu a melhores percentuais de remoção de benzeno na Etapa I (Figura 7).

Estudos demonstram que a utilização de fonte de carbono mais facilmente assimiláveis é benéfica na biodegradação de alguns compostos recalcitrantes, pois favorece o aumento de biomassa e ganho de energia resultando em melhores remoções desses compostos. Na Etapa II, o aumento da eficiência observado foi atribuído à retirada da glicose do meio. Dessa forma, a presença da glicose teria contribuído para que os microrganismos a consumissem preferencialmente em relação ao etilbenzeno (RODRIGUES, K., 2017).

Figura 6 - Concentração de benzeno, tolueno, etilbenzeno e xileno no afluente e efluente ao reator de leito fixo e fluxo contínuo ao longo das coletas da Etapa I.
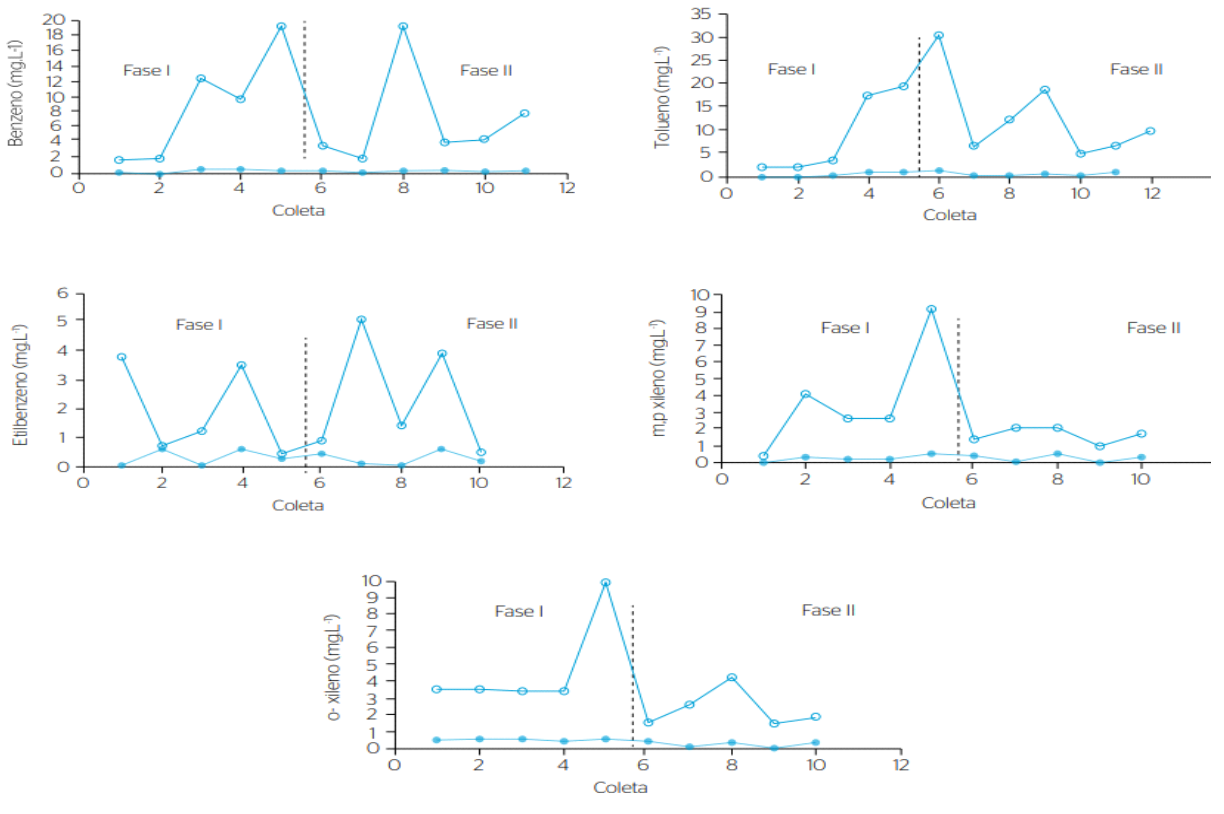

- Entrada - Saída 
Figura 7 - Concentração de benzeno, tolueno, etilbenzeno e xileno no afluente e efluente ao reator de leito fixo e fluxo contínuo ao longo das coletas da Etapa II.
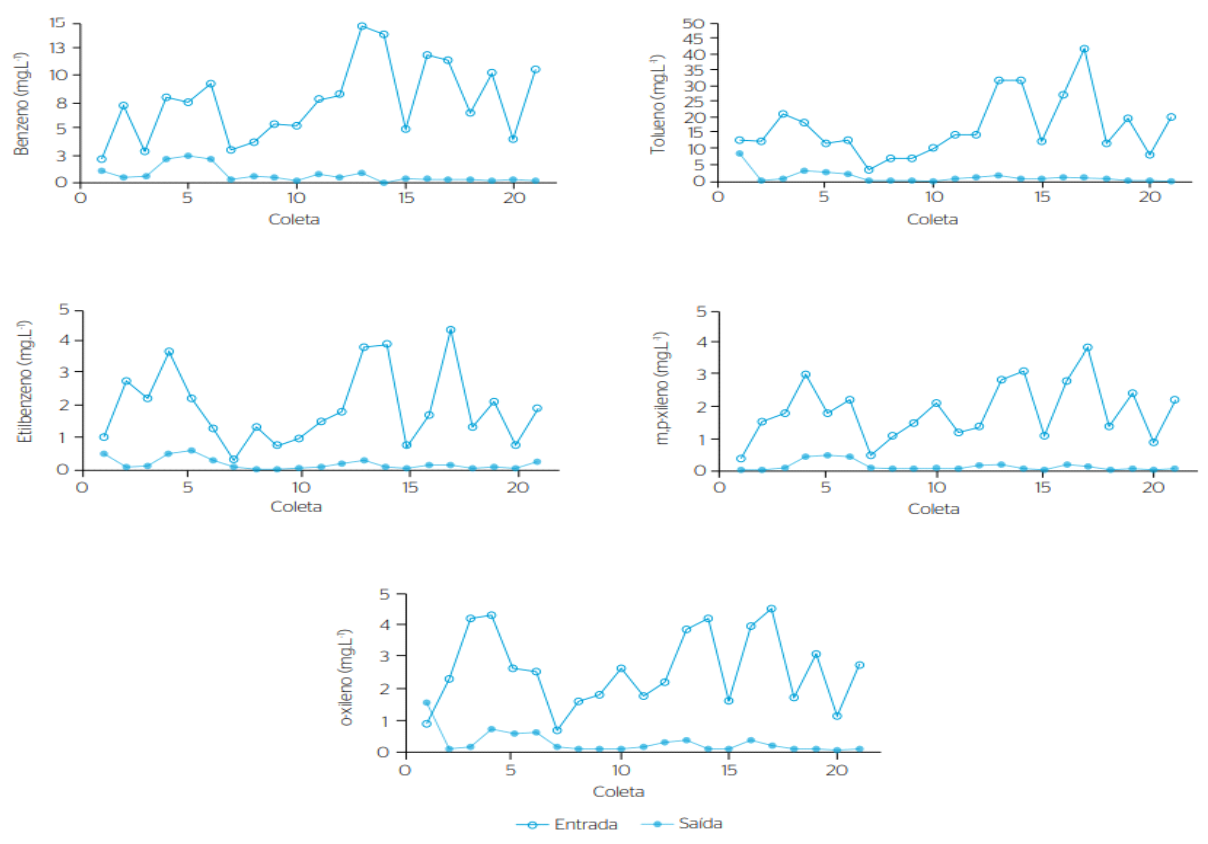

\section{Considerações Finais}

A degradação de hidrocarbonetos utilizando técnicas de biorremediação pode ser uma saída importante para diminuição desses compostos altamente tóxicos para o meio ambiente. Nota-se que a utilização dos microrganismos é pouco invasiva ao meio ambiente e não há uma síntese de metabólitos secundários, ou compostos que podem afetar a biota da amostra a ser tratada. 
https://doi.org/10.31692/ICIAGRO.2020.0393

Observa-se também que a utilização dos microrganismos, bactérias ou fungos, depende do composto que precisa ser degradado e o ambiente a ser remediado, o uso dos dois grupos de microrganismos é eficaz na degradação dos BTEX.

Os métodos físico-químicos, por sua vez, são efetivos em processos de remediação, no entanto podem alterar importantes condições do ambiente que está sendo remediado, principalmente a biota local, outro ponto negativo do uso desses métodos é o uso de agentes químicos tóxicos que podem causar contaminações secundárias.

\section{Referências}

ANDRADE, J. A., AUGUSTO, F., JARDIM, I. C., Biorremediação de solos contaminados por petróleo e seus derivados. Ecl. química, Volume 35, n 3, 2016.

BEZERRA, J. K. A., Remoção de benzeno e tolueno em solução aquosa por adsorção utilizando carvão ativado produzido a partir do lodo doméstico. Universidade federal do Rio Grande do Norte, 2017.

CAVALLARI, F., Caracterização geofísica de contaminação por hidrocarbonetos em acidente ferroviário. Universidade Estadual paulista “Júlio de Mesquita Filho”. 2017.

CETESB, Avaliação de Benzeno; Tolueno; o-Xileno; m, p-Xileno e Etilbenzeno na Atmosfera da Estação de Monitoramento de Pinheiros - Município de São Paulo - SP 2013 - 2014. Companhia ambiental do estado de São Paulo, diretoria de engenharia e qualidade ambiental, 2016.

COSTA, D. F.; GOLDBAUM, M., Contaminação química, precarização, adoecimento e morte no trabalho: benzeno no Brasil. Departamento de Medicina Preventiva, Faculdade de Medicina, USP. Ciência e saúde coletiva, 2017.

GOUMA, S., FRAGOEIRO, S., BASTOS, A.C., MAGAN, N. Bacterial and Fungal Bioremediation Strategies, pp. 301 - 323, 2014.

GUO, X.; ZHONG, W.; CHEN, Y.; ZHANG, W.; REN, J.; GAO, A.; Benzene metabolites trigger pyroptosis and contribute to haematotoxicity via TET2 directly regulating the Aim2/Casp1 pathway. EBioMedicine, P.578-589 (2019).

GHOREISHI, G. et al. Bioremediation capability and characterization of bacteria isolated from petroleum contaminated soils in Iran. Sustainable Environment Research, 2017.

HEIDERSCHEIDT, D. et al. Conceitos aplicados à poluição do solo decorrente do derrame de petróleo e seus derivados. Revista Maiêutica Indaial, v. 4, n. 1, p. 7-14, 2016. 
JASMINE, J., MUKHERJI, S., Impact of bioremediation strategies on slurry phase treatment of aged oily sludge from a refinery. Journal of Environmental Management, Volume 246, 15 September 2019, Pages 625-635.

KURZBAUM, E., RAIZNER, Y., COHEN, O., SUCKEVERIRENE, R. Y., Kulikov, A., HAKIMI, B., MENASHE, O. Encapsulated Pseudomonas putida for phenol biodegradation: Use of a structural membrane for construction of a well-organized confined particle. Science of The Total Environment, 2017 121, 37-45.

LEAL, A. J. et al. Changes in the microbial community during bioremediation of gasolinecontaminated soil. Brazilian journal of Microbiology, p. 343, 2016.

LEITE, M. S.; MESQUITA, M. V., Processos de remediação para hidrocarbonetos e etanol resultantes da contaminação dos postos de combustíveis. Revista de engenharia e tecnologia aplicada UNG, v.1, n 1, 2017.

LOOMIS, D., GUYTON, K. Z., GHISSASSI, F., GROSSE. Y., BOUVARD, V., TALLAA, L. B., GUHA, N., VILAHUR, N., MATTOCK, H., STRAIF, K., Agência Internacional de Pesquisa em Grupo de Trabalho sobre Monografia do Câncer Agência Internacional de Pesquisa em Câncer, Lyon, França. v18, 2017.

MAZZEO, D. E. C., LEVY, C. E., DE ANGELYS, D. de F., MARIN-MORALES, M. A.. BTEX biodegradation by bacteria from effluents of petroleum refinery. Science of The Total Environment, 2016, 408(20), 4334-4340.

MORAES, B. P., Petróleo. CPRM Serviço geológico do Brasil,2014 Disponível em: $<$ http://www.cprm.gov.br/publique/Redes-Institucionais/Rede-de-Bibliotecas---RedeAmetista/Canal-Escola/Petroleo-1256.html $>$. Acesso em 12 de maio de 2019.

MOREIRA, P. A. R., Derrames de hidrocarbonetos no mar: uma avaliação das questões operacionais. Faculdade de engenharia universidade do porto, 2016. Disponível em: $\langle$ https://repositorio-aberto.up.pt/bitstream/10216/82721/2/118504.pdf>. Acesso em: 24 de julho de 2019.

NESPECA, M. G., Aplicação de espectroscopia no infravermelho próximo e análise multivariada para identificação e quantificação de hidrocarbonetos totais do petróleo em solo. Universidade Estadual Paulista, 2018.

OLIVEIRA, G., MARCATO, F. S., SCAZUFCA P., PIRES, R. C., Perdas de água 2018 (SNIS 2016): Desafios para a disponibilidade hídrica e avanço da eficiência do saneamento básico. GO associados, saneamento Brasil, Maio 2018.

OLIVEIRA, L.; Avaliação da capacidade de biodegradação de benzeno, tolueno, etilbenzeno e isômeros de xilenos por bactéria de área contaminada. Universidade de São paulo- instituto de ciência biomédica, 2017. 
https://doi.org/10.31692/ICIAGRO.2020.0393

ORYAN, A., JALILI, M., KAMALI, A., NIKAHVAL, B., The concurrent use of probiotic microorganism and collagen hydrogel/scaffold enhances burn wound healing: An in vivo $\begin{array}{llll}\text { evaluation. } & \text { Burns, } & \text { Volume } & \text { HYPERLINK }\end{array}$ "https://www.sciencedirect.com/science/journal/03054179/44/7"Issue HYPERLINK "https://www.sciencedirect.com/science/journal/03054179/44/7" 7, November 2018, Pages 17751786.

OSORIO, D. S. G., Estudo comparativo de sílicas mesoporosas organofuncionalização magnéticas como adsorventes de benzeno, etilbenzeno, tolueno, xileno (BTEX). Universidade de São Paulo, 2018.

PRABHAKARAN, D. C., BENITEZ, V. B., SIVRY, Y., GELABERT, A., RIOTTE, J., SUBRAMANIAN, S., Mechanistic studies on the bioremediation of Cr(VI) using Sphingopyxis macrogoltabida SUK2c, a Cr(VI) tolerant bacterial isolate. Biochemical Engineering Journal, 2019.

RODRIGUES, K., OLIVEIRA, P. C., MOREIRA, I. C., FIRMINO, S. F., WANDERLEY, C. R., ARAÚJO, R., MARINHO, G., Remoção de BTEX por fungos em reator aeróbio de escoamento contínuo. Eng Sanit Ambient, v.22, n.4, jul/ago 2017, p.809-820.

SILVA, I. S.; LIMA, S. G.; Abordagem física de compostos orgânicos. Atena editora, v. 1,p. 3, 2019.

SILVA, W. M., Utilização de microrganismos na biorremediação de solo contaminado por derivados de petróleo. Universidade Estadual paulista “Júlio de Mesquita Filho", 2018.

SOARES, M. V.; ÁVILA, D.S., Exposição ao tolueno altera desenvolvimento, comportamento e induz aumento de eventos apoptóticos em caenorhabditis elegans. Universidade federal do Pampa, 2016.

SOUSA, K. C. et al. Biorremediação de solos contaminado por hidrocarbonetos utilizando fungos. Revista da Universidade Vale do Rio Verde, Três Corações, v. 14, n. 2, p. 43-52, ago./dez. 2016 .

WANG, X., XUE, L., CHANG, S., HE, X., FAZ, T., WU, J., NIU, J., EMANEGHEMI, B., Bioremediation and metabolism of clothianidin by mixed bacterial consortia enriched from contaminated soils in Chinese greenhouse. Process HYPERLINK "https://www.sciencedirect.com/science/journal/13595113" Biochemistry, Volume HYPERLINK "https://www.sciencedirect.com/science/journal/13595113/78/supp/C" 78 , March 2019, Pages 114-122.

ZHOU, Z., LIUA, X., SUNA, K., LINA, C., MAA, J., HEA, M., OUYANG, W., Persulfate-based advanced oxidation processes (AOPs) for organic contaminated soil remediation: A review. Chemical Engineering Journal, 2019. 